\title{
Deep space and hidden depths: understanding the evolution and ecology of fungal entomopathogens
}

\author{
Helen E. Roy • Eoin L. Brodie • Dave Chandler • \\ Mark S. Goettel • Judith K. Pell • \\ Eric Wajnberg · Fernando E. Vega
}

Received: 22 September 2009/Accepted: 15 October 2009/Published online: 17 November 2009

(C) International Organization for Biological Control (IOBC) 2009

\begin{abstract}
Entomopathogens are important natural enemies of many insect and mite species and as such have been recognised as providing an important ecosystem service. Indeed, fungal entomopathogens have been widely investigated as biological control agents of pest insects in attempts to improve the sustainability of crop protection. However, even though our understanding of the ecology of fungal entomopathogens has vastly increased since the early 1800s, we still require in-depth ecological research that can expand our scientific horizons in a manner that facilitates widespread adoption of these organisms as efficient biological control agents. Fungal entomopathogens have evolved some intricate interactions
\end{abstract}

H. E. Roy $(\bowtie)$

NERC Centre for Ecology \& Hydrology, Wallingford, Oxfordshire OX10 8BB, UK

e-mail: Hele@ceh.ac.uk

E. L. Brodie

Ecology Department, Earth Sciences Division, Lawrence

Berkeley National Laboratory, Berkeley, CA 94720, USA

D. Chandler

Warwick HRI, University of Warwick, Wellesbourne,

Warwick CV35 9EF, UK

M. S. Goettel

Agriculture and Agri-Food Canada, Lethbridge Research Centre, 5403-1 Avenue South, P.O. Box 3000,

Lethbridge, AB T1J 4B1, Canada with arthropods, plants and other microorganisms. The full importance and complexity of these relationships is only just becoming apparent. It is important to shift our thinking from conventional biological control, to an understanding of an as yet unknown "deep space". The use of molecular techniques and phylogenetic analyses have helped us move in this direction, and have provided important insights on fungal relationships. Nevertheless, new techniques such as the PhyloChip and pyrosequencing might help us see beyond the familiar fields, into areas that could help us forge a new understanding of the ecology of fungal entomopathogens.

\footnotetext{
J. K. Pell

Department of Plant and Invertebrate Ecology,

Rothamsted Research, Harpenden, Hertfordshire AL5

2JQ, UK

E. Wajnberg

INRA, 400 Route des Chappes, BP 167, 06903 Sophia

Antipolis Cedex, France

F. E. Vega

Sustainable Perennial Crops Laboratory, United States Department of Agriculture, Agricultural Research Service, Building 001, BARC-West Beltsville, MD 20705, USA
} 
Keywords Ecology · Evolution ·

Entomopathogenic fungi · Biological control ·

Tri-trophic interactions $\cdot$ Modelling .

Rhizosphere · Endophytes · Behavioural ecology ·

Molecular tools

Fungi have a profound impact on global ecosystems. They modify our habitats and are essential for many ecosystem functions Blackwell et al. (2006).

It has been estimated that the Kingdom Fungi consists of 1.5 million species (Hawksworth 2001; Mueller and Schmit 2007; Schmit and Mueller 2007), with approximately 110,000 described species (Kirk et al. 2008). Of these, 700 species in 90 genera are recognized as insect pathogens (Roberts and Humber 1981), and approximately 170 pest control products have been developed based on at least 12 species of fungal entomopathogens (de Faria and Wraight 2007). Undoubtedly, fungal entomopathogens are important natural enemies of many insect and mite species and as such, provide an important ecosystem service contributing to pest control with minimal detectable negative effects on the environment (Vestergaard et al. 2003). However, the small subset of fungi developed as biological control agents have had limited success. Our ability to employ them effectively and reliably for pest control in the field has not matched up to expectations (Vestergaard et al. 2003; Chandler et al. 2008; Vega et al. 2009). In part, this may be because of variable and unpredictable levels of efficacy compared to chemical pesticides (Waage 1997; Vega et al. 2009), but we also lack some basic understanding of their ecology and evolution (Vega et al. 2009).

The importance of basic knowledge, theory and predictive ability in the use of biological control agents has been recognised for some time (Gurr et al. 2000). However, the dearth of basic information on fungal entomopathogens is pronounced even though these organisms have historically dominated the field of microbial control (Lord 2005). Vega et al. (2009) have proposed the need for "a new paradigm for fungal entomopathogens that should refocus our efforts and hopefully lead to exciting new findings." In this special issue of BioControl we report on some of the latest research, innovations and ideas relating to fungal entomopathogens within an ecological context.
One of the most significant challenges facing insect pathologists is to understand the evolutionary history and relationships amongst fungal entomopathogens. Intricate interactions with arthropods, plants and other microorganisms are evident, but the full importance and complexity of these relationships is just becoming apparent. The advent of new molecular tools over the last few decades has dramatically improved the resolution of fungal systematics and there have been huge advances in this field (Blackwell et al. 2006; Hibbett et al. 2007; Humber 2008; Blackwell 2009; Enkerli and Widmer 2009). The acquisition of a phylogeny enables us to examine evolutionary relationships and better understand and predict ecological interactions (Blackwell 2009). Molecular tools will provide methods for examining the host-pathogen dynamics in complex environments (Enkerli and Widmer 2009). Enkerli and Widmer (2009) comprehensively review the tools available within the context of population ecology studies.

Meyling and Hajek (2009) provide an excellent background to ecological interactions relevant to fungal entomopathogens from a community ecology perspective. An ecological context is important for increasing our empirical understanding of host-parasite interactions and improving the efficacy of these microbes as biological control agents. Fungal entomopathogens often exist as patches in a spatially heterogeneous matrix (Rodríguez and Torres-Sorando 2001) and metapopulation dynamics could be particularly pertinent to describing these spatially distinct populations that are connected by dispersal. Meyling and Hajek (2009) describe how insects and their fungal pathogens could be used as model species for exploring metapopulation theory using experimental and predictive models.

In recent years there have been intriguing advances in our appreciation of the role of fungal entomopathogens beyond their applied role as biological control agents of insects. Pathogens have traditionally been neglected in life history studies and often considered as having negligible impact (Hawkins et al. 1997). Hesketh et al. (2009) review the role of fungal entomopathogens as natural enemies of insects in semi-natural habitats, describing the theoretical host-pathogen models available to examine their role in population regulation. The need to consider the complexity, and particularly the heterogeneity, of semi-natural habitats within the context 
of theoretical models and as a framework for empirical studies is highlighted. However, Hesketh et al. (2009) acknowledge that fundamental gaps in our understanding of fungal entomopathogens from an ecological perspective, coupled with a lack of empirical data to test theoretical predictions, is impeding progress.

Ecological understanding has never been more vital than in this period of unprecedented environmental change:

Changes in biodiversity due to human activities were more rapid in the past 50 years than at any time in human history, and the drivers of change that cause biodiversity loss and lead to changes in ecosystem services are either steady, show no evidence of declining over time, or are increasing in intensity (Millennium Ecosystem Assessment 2005).

Many studies on the effects of the major drivers of biodiversity loss (habitat destruction, invasive species, exploitation, climate change and pollution) involve just one trophic level and often just one species. Fungal entomopathogens provide an additional trophic level that should be included in such studies, particularly in relation to climate change and habitat destruction (Roy and Cottrell 2008; Roy et al. 2009). Cory and Ericsson (2009) review the literature on tri-trophic interactions encompassing fungal entomopathogens. The promising roles of plant volatiles and plant surface chemistry on ecological interactions between host insects and their pathogenic fungi are described. Although intriguing concepts such as the "bodyguard hypothesis" have been examined and demonstrated for natural enemies such as parasitoids and predators, there is a lack of empirical evidence for this in fungal entomopathogens. This is likely because there has simply been limited research in this field. Cory and Ericsson (2009) assess the relevance of plant-mediated effects on fungal entomopathogens and urge researchers to focus work on the considerable gaps in knowledge concerning fungal entomopathogens and tritrophic interactions.

Behavioural ecology will be critical in the exploration of tritrophic interactions. Baverstock et al. (2009) provide a review of fungal entomopathogens and insect behaviour. The behavioural response of an insect to a fungal pathogen will not only have a direct effect on the efficacy of the fungus as a biological control agent but also provide us with a model system for understanding interactions within guilds. Simple laboratory bioassays can provide a measure of insect mortality in the presence of a pathogen but experiments designed to include elements of spatial complexity are critical to improving accuracy of predictions. The papers reviewed by Baverstock et al. (2009) demonstrate this and reveal manipulations of host behaviour induced by fungi and countermeasures employed by the host (Roy et al. 2006). The often complex interactions between fungus and host are being unravelled through eloquent research and the importance of these often subtle behavioural modifications in determining the success or failure of biological control cannot be underplayed.

The opportunities and challenges provided by the soil environment, and specifically the rhizosphere, have long been recognised (Vega et al. 2009) but only now are the subtleties slowly being revealed (Bruck 2009). There is no doubt that the ecology of fungal entomopathogens in the rhizosphere is a neglected area of research within insect pathology. A better understanding of their ecology in the rhizosphere will not only help in the development of successful microbial control strategies against root-feeding insect pests, but is also certain to reveal intriguing insights into the subterranean "hidden depths" of fungal entomopathogens.

Ownley et al. (2009) review the ecology and evolution of fungal entomopathogens as antagonists of plant pathogens. Simultaneous biological control of both insect pests and plant pathogens has been reported for the hypocrealean fungal entomopathogens, Beauveria bassiana and Lecanicillium spp. and accumulating evidence shows that Beauveria spp. can colonize a wide array of plant species endophytically. Furthermore, traits that are important for insect pathogenicity are also involved in pathogenicity to phytopathogens.

From 1845 to 1916, Elie Metchnikoff assessed an insect disease of wheatchafers later identified as the hypocrealean fungus Metarhizium anisopliae (Lord 2005). These early studies inspired many to focus their research on assessing the potential of fungal entomopathogens as microbial control agents. A series of papers in this special issue of BioControl explore advances in their use for biological control of pest insects. Jackson et al. (2009) eloquently describe the importance of linking ecology with formulation and 
production of fungal entomopathogens for biological control. The commercial drivers of formulation (maximising yield, storage stability and ease of application) are often in conflict with ecological considerations. However, efficacy can be improved dramatically by considering ecological factors such as the importance of environmental conditions on the host-pathogen interaction (Jackson et al. 2009).

Biological control strategies include classical, inundative augmentation and conservation approaches. Hajek and Delalibera (2009) examine the use of fungal entomopathogens in classical biological control and conclude that they have been used more frequently than other types of pathogens and provide a sustainable avenue for controlling arthropod pests, especially the increasing numbers of invasive species. Inundative biological control strategies rely on the released organism exerting control without subsequent transmission and reproduction in a similar way to a synthetic pesticide; the chemical paradigm. Jaronski (2009) aptly demonstrates the drawbacks of taking this approach in isolation with fungal entomopathogens. In most cases, effective application of sufficient inoculum to rapidly reduce pest numbers to below economic threshold levels is financially and logistically prohibitive. Biotic, abiotic and economic realities certainly restrict such an approach in most field situations although there have been some notable successes in controlling pest insects in glasshouses. Through a better understanding of the ecology of fungal entomopathogens and the dynamics of the pest, crop and environment, it may be possible to employ inundative application of fungi within ecologically based integrated pest management systems. However, it will be imperative that such strategies encompass the complex and multifaceted interactions that the released organism must contend with. The review on conservation biological control by Pell et al. (2009) explores the novel ways in which fungal entomopathogens can be enhanced in the environment. Understanding the dynamics of fungal entomopathogens at the field and landscape scale is imperative for implementing conservation biological strategies. There have been a number of eloquent studies demonstrating the potential of such an approach and these are comprehensively reviewed by Pell et al. (2009).

The realm of ecology is vast and deciphering insect-fungal pathogen interactions within an ecological context will take us on voyages beyond our imagination. New and innovative methods will provide the inspiration to explore the hidden depths and deep space of these interactions. The PhyloChip microarray hybridization technique might point at what the future holds for mycological research. At present, the PhyloChip allows for the identification of bacterial and archaeal organisms using 16S rRNAtargeted oligonucleotide microarrays (Brodie et al. 2007; DeSantis et al. 2007). The method takes advantage of the variation in the 16S rRNA gene to capture the broad range of microbial diversity that may be present in a given sample, without the need for microbial cultivation. This high-throughput technique makes it possible to identify overall microbial diversity, and combined with dissection of specific insect tissues (e.g., foregut, midgut, hindgut), determine microbial communities in these tissues. A version is currently being developed for the analysis of fungal community diversity. Similarly, sequencing technologies such as 454-pyrosequencing now permit large numbers of shorter sequences (pyrotags) to be obtained from a large number of samples by employing sequence barcoding techniques (Hamady et al. 2008). These approaches allow deeper profiling of complex microbial communities from the deep-sea (Sogin et al. 2006) to the gut microbiota of humans and 59 other mammals (Ley et al. 2008). Greif and Currah (2007) have shown that fungal entomopathogens are common components of the surface mycota of arthropods, and that they are not necessarily restricted to diseased insects. Once a microarray technique similar to the PhyloChip or pyrotag sequencing has been developed for fungal entomopathogens, what would their uses reveal in insects? Will fungal entomopathogens be found to be common inhabitants of the cuticle of uninfected insects? Could they also be common internal inhabitants of uninfected insects? Furthermore, using microarray techniques for sampling fungal entomopathogens as plant endophytes might reveal that they are much more common and globally distributed than is presently thought. Would the same situation occur in the rhizosphere? If the answer to any of these questions were positive, what would this imply for our understanding of fungal entomopathogens?

There might be a "deep space" that will only be revealed when we start to decipher the myriad fungal inhabitants in insects and plants, which at present 
remain in "hidden depths". The importance of these interactions has been superbly described by Berenbaum and Eisner (2008):

There is no limit to what remains to be discovered in that interactive zone between macroorganism and microbe, where so many biological mutualisms and antagonisms play out. Microbes blanket the planet, and in their infinite variety they must be involved in infinite interactions. Deciphering these could lead to a vast increase in ecological knowledge, as well as to the isolation of natural products of unforeseen function.

Let the adventure begin!

Acknowledgments The Rockefeller Foundation Bellagio Study and Conference Center in Italy hosted the June 2008 meeting Entomopathogenic fungi in sustainable agriculture: use against insects and beyond (organised by F. E. Vega and M. S. Goettel). This meeting was the inspiration for this special edition and we express our sincere gratitude to the staff at The Rockefeller Foundation and at the Bellagio Study and Conference Centre. HER is supported by the Natural Environment Research Council. JKP is supported by the Department for Environment, Food and Rural Affairs of the United Kingdom (Defra) and the Biotechnology and Biological Sciences Research Council of the United Kingdom (BBSRC). Rothamsted Research is an Institute of BBSRC.

\section{References}

Baverstock J, Roy H, Pell JK (2009) Entomopathogenic fungi and insect behaviour: from unsuspecting hosts to targeted vectors. BioControl. doi: 10.1007/s10526-009-9238-5 (this SI)

Berenbaum M, Eisner T (2008) Bugs' bugs. Science 322:52-53

Blackwell M (2009) Fungal evolution and taxonomy. BioControl. doi:10.1007/s10526-009-9243-8 (this SI)

Blackwell M, Hibbett DS, Taylor JW, Spatafora JW (2006) Research coordination networks: a phylogeny of the kingdom Fungi (Deep Hypha). Mycologia 98:829-837

Brodie EL, DeSantis TZ, Moberg Parker JP, Zubietta IX, Piceno YM, Andersen GL (2007) Urban aerosols harbor diverse and dynamic bacterial populations. Proc Natl Acad Sci USA 104:299-304

Bruck D (2009) Fungal entomopathogens in the rhizosphere. BioControl. doi:10.1007/s10526-009-9236-7 (this SI)

Chandler D, Davidson G, Grant WP, Greaves J, Tatchell GM (2008) Microbial biopesticides for integrated crop management: an assessment of environmental and regulatory sustainability. Trends in Food Science \& Technology 19:275-283

Cory JS, Ericsson JD (2009) Fungal entomopathogens in a tritrophic context. BioControl. doi:10.1007/s10526-0099247-4 (this SI) de Faria MR, Wraight SP (2007) Mycoinsecticides and mycoacaricides: a comprehensive list with worldwide coverage and international classification of formulation types. Biol Control 43:237-256

DeSantis TZ, Brodie EL, Moberg JP, Zubieta IX, Piceno YM, Andersen GL (2007) High-density universal 16S rRNA microarray analysis reveals broader diversity than typical clone library when sampling the environment. Microb Ecol 53:371-383

Enkerli J, Widmer F (2009) Molecular ecology of fungal entomopathogens: the molecular genetic tools and their application. BioControl. doi:10.1007/s10526-009-9251-8 (this SI)

Greif MD, Currah RS (2007) Patterns in the occurrence of saprophytic fungi carried by arthropods caught in traps baited with rotted wood and dung. Mycologia 99:7-19

Gurr GM, Barlow ND, Memmott J, Wratten SD, Greathead DJ (2000) A history of methodological, theoretical and empirical approaches to biological control. In: Gurr G, Wratten SD (eds) Biological control: measures of success. Kluwer Academic Publishers, Dordrecht, The Netherlands, pp 3-37

Hajek AE, Delalibera I (2009) Fungal pathogens as classical biological control agents against invasive arthropods. BioControl. doi:10.1007/s10526-009-9253-6 (this SI)

Hamady M, Walker JJ, Harris JK, Gold NJ, Knight R (2008) Error-correcting barcoded primers for pyrosequencing hundreds of samples in multiplex. Nat Methods 5: 235-237

Hawkins BA, Cornell HV, Hochberg ME (1997) Predators, parasitoids and pathogens as mortality agents in phytophagous insect populations. Ecology 78:2145-2152

Hawksworth DL (2001) The magnitude of fungal diversity: the 1.5 million species estimate revisited. Mycol Res 105:1422-1432

Hesketh H, Roy HE, Eilenberg J, Pell JK, Hails RS (2009) Modelling complexity: entomopathogenic fungi in seminatural populations of insects. BioControl. doi: 10.1007/s10526-009-9249-2 (this SI)

Hibbett DS, Binder M, Bischoff JF, Blackwell M, Cannon PF, Eriksson OE, Huhndorf S, James T, Kirk PM, Lücking R, Thorsten Lumbsch H, Lutzoni F, Brandon Matheny P, McLaughlin DJ, Powell MJ, Redhead S, Schoch CL, Spatafora JW, Stalpers JA, Vilgalys R, Aime MC, Aptroot A, Bauer R, Begerow D, Benny GL, Castlebury LA, Crous PW, Dai YC, Gams W, Geiser DM, Griffith GW, Gueidan C, Hawksworth DL, Hestmark G, Hosaka K, Humber RA, Hyde KD, Ironside JE, Kõljalg U, Kurtzman CP, Larsson K-H, Lichtwardt R, Longcore J, Miądlikowska J, Miller A, Moncalvo JM, Mozley-Standridge S, Oberwinkler F, Parmasto E, Reeb V, Rogers JD, Roux C, Ryvarden L, Sampaio JP, Schüßler A, Sugiyama J, Thorn RG, Tibell L, Untereiner WA, Walker C, Wang Z, Weir A, Weiss M, White MM, Winka K, Yao YJ, Zhang N (2007) A higher-level phylogenetic classification of the Fungi. Mycol Res 111:509-547

Humber RA (2008) Evolution of entomopathogenicity in fungi. J Invertebr Pathol 98:262-266

Jackson M, Dunlap CA, Jaronski S (2009) Ecological considerations in producing and formulating fungal entomopathogens for use in insect biocontrol. BioControl. doi:10.1007/s10526009-9240-y (this SI) 
Jaronski S (2009) Ecological factors in the inundative use of entomopathogenic fungi. BioControl. doi:10.1007/s10526009-9248-3 (this SI)

Kirk PM, Cannon PF, Minter DW, Stalpers JA (2008) Dictionary of the fungi, 10th edn. CAB International, Wallingford, UK

Ley RE, Hamady M, Lozupone C, Turnbaugh PJ, Ramey RR, Bircher JS, Schlegel ML, Tucker TA, Schrenzel MD, Knight R, Gordon JI (2008) Evolution of mammals and their gut microbes. Science 320:1647-1651

Lord J (2005) From Metchnikoff to Monsanto and beyond: the path of microbial control. J Invertebr Pathol 89:19-29

Meyling NV, Hajek AE (2009) Principles from community and metapopulation ecology and their application to fungal entomopathogens. BioControl. doi:10.1007/s10526-0099246-5 (this SI)

Millennium Ecosystem Assessment (2005) Ecosystems and human well-being: biodiversity synthesis. World Resources Institute, Washington, DC

Mueller GM, Schmit JP (2007) Fungal biodiversity: what do we know? What can we predict? Biodivers Conserv 16:1-5

Ownley B, Gwinn KD, Vega FE (2009) Endophytic fungal entomopathogens with activity against plant pathogens: ecology and evolution. BioControl. doi:10.1007/s10526009-9241-x (this SI)

Pell JK, Hannam J, Steinkraus DS (2009) Conservation biological control using entomopathogenic fungi. BioControl. doi:10.1007/s10526-009-9245-6 (this SI)

Roberts DW, Humber RA (1981) Entomogenous fungi. In: Cole GT, Kendrick B (eds) Biology of conidial fungi. Academic Press, New York, pp 201-236

Rodríguez DJ, Torres-Sorando L (2001) Models of infectious diseases in spatially heterogeneous environments. Bull Math Biol 63:547-571

Roy HE, Cottrell T (2008) Forgotten natural enemies: interactions between coccinellids and insect-parasitic fungi. European Journal of Entomology 105:391-398

Roy HE, Steinkraus D, Eilenberg E, Pell JK, Hajek A (2006) Bizarre interactions and endgames: entomopathogenic fungi and their arthropod hosts. Ann Rev Entomol 51:331-357

Roy HE, Hails RS, Hesketh H, Roy DB, Pell JK (2009) Beyond biological control: non-pest insects and their pathogens in a changing world. Insect Conservation and Biodiversity 2:65-72

Schmit JP, Mueller GM (2007) An estimate of the lower limit of global fungal diversity. Biodivers Conserv 16:99-111

Sogin ML, Morrison HG, Huber JA, Mark Welch D, Huse SM, Neal PR, Arrieta JM, Herndl GJ (2006) Microbial diversity in the deep sea and the underexplored "rare biosphere". Proc Natl Acad Sci USA 103:12115-12120

Vega FE, Goettel MS, Blackwell M, Chandler D, Jackson MA, Keller S, Koike M, Maniania NK, Monzón A, Ownley BH, Pell JK, Rangel DEN, Roy HE (2009) Fungal entomopathogens: new insights on their ecology. Fungal Ecol 2:149-159

Vestergaard S, Cherry A, Keller S, Goettel M (2003) Safety of hyphomycete fungi as microbial control agents. In: Hokkanen HMT, Hajek AE (eds) Environmental impacts of microbial insecticides. Kluwer Academic Publishers, Dordrecht, pp 35-62
Waage JK (1997) Biopesticides at the crossroads: IPM products or chemical clones? In Evans HF (Chair) Microbial insecticides: novelty or necessity? British Crop Protection Council Symposium Proceedings No. 68, Farnham, UK, pp 11-20

\section{Author Biographies}

Helen E. Roy leads zoological research in the Biological Records Centre at the NERC Centre for Ecology \& Hydrology (UK). The focus of her research is insect community interactions with particular emphasis on the effects of environmental change. She is an associate editor of BioControl.

Eoin L. Brodie develops and applies culture independent approaches to analyze microbial communities and conducts research on climate change impacts on their structure and function.

Dave Chandler is an insect pathologist at the University of Warwick, UK. He has studied entomopathogenic fungi for just over 20 years. He has particular interests in entomopathogenic fungi as biocontrol agents of horticultural crops, fungal physiology and ecology, and the pathogens of honeybees.

Mark S. Goettel is an insect pathologist at the Lethbridge Research Centre of Agriculture \& Agri-Food Canada, specializing in the development of entomopathogenic fungi as microbial control agents of insects. In addition to this research, he has been extensively involved in the review and revision of the regulations for registration of microbial control agents and has addressed regulatory and safety issues at the international level. He is currently President of the Society for Invertebrate Pathology and has been Editor-in-Chief of Biocontrol Science \& Technology since 2000 .

Judith K. Pell heads the Insect Pathology Group in the Department for Plant and Invertebrate Ecology at Rothamsted Research, UK. She leads research on the ecology of entomopathogenic fungi, to elucidate their role in population regulation and community structure and to inform biological control strategies. Specifically: intraguild interactions; the relationships between guild diversity, habitat diversity and ecosystem function; pathogen-induced host behavioural change.

Eric Wajnberg is a population biologist specialised in behavioural ecology, statistical modelling and population genetics. He is also an expert in biological control, with more than 20 years experience of working with insect parasitoids. He has been the Editor in Chief of BioControl since 2006.

Fernando E. Vega is an entomologist with the United States Department of Agriculture, Agricultural Research Service, in Beltsville, Maryland, USA. He conducts research on biological methods to control the coffee berry borer, the most important insect pest of coffee throughout the world. He is co-editor, with Meredith Blackwell, of Insect-Fungal Associations: Ecology and Evolution, published by Oxford University Press in 2005, and serves as an Editorial Board Member for Fungal Ecology. 